patlent bears weight on the limb atter the splints have been removed the bone will very probably bend.

(e) Ataxia.-Probably the best form of treatment is by Frenkel's exercises, and even in very bad cases improvement is marked. When the ataxia is extreme and the patient unable to stand and walk, simple movements must be made whlle in bed. The first of these movements is that of raising one leg slowly and steadily to a fixed point, then bringing the heel down on a fixed polnt. $A$ board can be used with notches, In which the heels are placed. The patient is then made to raise the foot and bring the heel down into another of the notches. These movements are persevered with several times esch das until the patient can perform them accurately. The nex advance is to train him to stand steadily, and then to walk. At first this can be greatly alded by the use of an apparatus 80 constructed with adjustable crutches on wheels, that part of the patient's weight is transferred from the lower limbs to the axillae and arms; afterwards he should exercise with the aid of sticks, then withou any support. He should next be made to walk bringing his foot down accurately on lines ruled on the floor. It is essential that the patient be impressed with the importance of making each step and movement in the precise way indicated. After some Improvement has taken place and the patient has gained confidence, he may practise the movements himself. The best results are obtained in patients who take interest themselves in the exerclses, and who are persevering in their attempts to carry out suggestions. It is important to give the patient every encouragement, and to try to help him to gain confidence in his own efforts. Movements for the arms suitable for each individual case can be devised. Every exercise must be made with great care. At first the movement should be practised for about a quarter of an hour two or three times a day, less or more according to the severity of the case; they should be stopped directly there is any sign of fatigue, and over-exertion must always be rigidly avoided. The exerclses ought to be carried out under the eye of the medical attendant. They should be persevered with for not less than a month, $\epsilon x$ cept when contraindicated by fatigue, or other untoward symptoms.

$X$ Rays.-In certain cases the $x$ rays should be tried. Dr. Byrom Bramwell, in speaking of the effects of the treatment and its possibilities, states, in a case in which the most careful dieting, rectal leeding, and medicinal treatment had practically failed to arrest the gastric crises, which were very severe and of $2 \frac{1}{2}$ years' duration the result was most remarkable. The $x$ rays were applled for five minutes every day to the dorsal reglon of the splnal column. Immediate and extraordinary Improvement resulted from the treatment, and the patient was able to digest potatoes, meat, etc., without pain or discomfort, and gained $10 \frac{1}{2} \mathrm{lb}$. In weight during the first week. There was a return of the symptoms in thls case they, however, were again relieved by the $x$ rays. Nothing is known as to the mode of action of the $x$ rays in cases of visceral and internal disease; it is probable that the improvement gained in locomotor ataxis is the result of a mental or psychical impression.

Thermal treatment may be obtained at Cheltenham, Buxton, Strathpeffer, and other places in this country; abrosd, at Nanheim, Aix-la-Chapelle, St. Moritz, etc. Cheltenham, the garden town of England, has many advantages; the mild climate, the level aspect, and the general attractive appearance make it eminently suitable for the tabetic. A new central sps at the Town Hall was Inaugurated by Dr. Goodhart on June 20th, 1906. The surrounding hills can be reached by electric car, where at $a$ height of nearly $1,000 \mathrm{ft}$. above sea level the air is most Invigorating. The most suitable temperature, as a rule, for baths ls about $80^{\circ} \mathrm{F}$. Sulphur baths are used, and are spoken highly of by some. Baths in general aid the circulation and are refreshing and comforting. The change of scene, regulation of diet, and general manage. ment to be obtained at a spa have a stimulating and helpful effeot on the mental and general condition allimportant to an ataxic patlent, and there is no doubt that considerable benefit sometimes results from such treatment.

Suspension.-Benefit has been noted from this, it was probably due to suggestion and to psychical effects. It is not a form of treatment to be recommended and is now verg rarely practised.
Electricity.-Both faradic and galvanic currents have been used, the former applied to the skin with a wire brush chlefly for the relief of pain, and with the hope of restoring sensation. The latter is best applied by means of two very large electrodes, one over the sacrum, the other higher up; the npper electrode is moved slowly up and down the splne, so as to vary the density withont rapid makes or breaks, the current being gradually ralsed to the maximum which can be borne. The object of this is to modify the nutrition of the cord. Electricity mas be tried for the paralysis which orcurs, and should be applied to the nerves and muscles which are affected.

Marriage.-Tabetic patients ought not to marry.

Climate.-Cold and damp aggravate the pains; an equable warm and dry climate is one most suitable.

Drug8.-Potassium iodide and mercury have been largely given, but most authorities agree that they have not much influence over the lesions of the disease. If the case is seen in an early stage these remedies should be used, and if a history of syphllis can be elicited, and especlally if the primary Infection occurred within, say, two years of the onset of tabetic symptoms, or if there has not been early and thorough treatment of the syphills, thes should be administered perseveringly. Potassium lodide may be combined with colchicum and alkalles when the pains are severe. Silver nitrate given in 1 .grain doses for $a$ long time often relieves and lessens the frequency of the pains, and may do some permanent good. Aluminium chloride may be given two or three times a day, and certainly with benefit, especially for the pains. Zinc phosphate is beneficial in some cases. Gold chloride has been used with good effects. Arsentc should be pushed and its general tonic effect is undoubtedly of service ; its combination with iron is sometimes advisable. Strychnine is a remedy constantly employed for the tonlc effect and is often of service. Ergot may be used in acute and subacate attacks, and it is recommended by Charcot for urinary troubles. Cannabis indica is serviceable in some cases for the relief of the pains. Calabar bean has some influence in improving muscular power and in retarding wasting in paralysis. Phenscetin and lactophenin are very useful for the relief of the pains, and also for control of arises and may be repeated. Antipyrin is used by many, but it is not without danger in large doses. An attack of pain will often yield after three or four doses of ten grains given at intervals of an hour. Sodium Ealicylate is worthy of trial when the pains are much in evidence. Nitroglycerine is very useful if there is increased arterial tension, then it may be given for a long time in increasing doses, with much benefit in relieving the crises and lessening the pain. Morphine is a remedy the use of which it is advisable to postpone as long as possible, but it may be a necessity if the distressing pain resists all other treatment; the smallest dose which will afford relief should be administered in the form of hypodermic injection. Sometimes it is also required for the gastralgia.

Animal Extracts.-Testicular juice, spinal cord, brain substance, spermin, have been tried but with very unsatisfactory results.

BIBLIOGRAPHY.

Allbutt, Clifford: System of Medicine, vol. vii. pt. iv

Keen and White: Textbook of Surgery,

Stewart, Purves: The Clinical significance of the Cerebro-spinal Fluid, Practitioner, vol. l区xv, No. 3 .

Clinical Journal, vols. v, vi. viii, 1894-5-6.

Year Book of Treatment, 1898.

\section{AN OPEN METHOD OF ETHER ADMINIS-} TRATION.*

BY FRANCI8 W. BAILEY, M.R.C.S.ENG., L.R.C.P.LOND,, HONORARY ANAESTHETIST TO THE ROYAL INFIRMARY, LIVERPOOL,
AND TO THE LIVEROOL DENTAL HOSPITAL.

THFrke are, of course, many known ways and means of administering ether, and I do not clsim any origlnalits for the method I am about to describe; bat I think it would be worth bringing to notice, although I do not commend it as the only way ether should be administered, but rather look upon it as an addition to the

* Read before a joint meeting of the Lancashire and Cheshire and North Wales Branches at Chester. 
anaesthetist's armamentarlúm. As the operating surgeon has several methods whlch he may adopt in the radical cure of hernia, $80 \mathrm{I}$ think it is advantageous not to be too stereotyped in our methods of administering an anaesthetic, and to suit the anaesthetic and its method of administration to the case and condition of the patient, for, after all, the personal element is a great factor in anaesthetic work.

Those members of the Association who visited the May0s' Hospital in Rochester. when at the annual meeting last year, have seen the method adopted, it is caid, in every case; but I must confess. I myself would not apply it In every case, becanse I do not think it suitable to all the different types of patlents one meets with here in England. Their babits may be different; elther it may be that the climatic conditions in this country are different, and so the rate of evaporation of ether is not the eame, or the ether itself may have a specific gravity unlike that used in America; whlch cause is at work I am not prepared to say.

I have long been an advocate for the open method of ether administration, using solely an Allis inhaler; but it Is not my purpose in this short note to enter into the pros and cons of the open or closed method; I wish to describe a method whlch appeals to me on account of the simplicity of the apparatus which we all possess, since it consists merely of a Skinner's inhaler, a plece of gauze or Gamgee tissue, and a bottle with a ganze wlck.

The Bottle and Wick.-An ordinary $6 \mathrm{oz}$. or $8 \mathrm{oz}$, mediclne bottle answers the purpose well; a slit is made in the side of the cork to allow of the passage of a strip of gauze, which ought to reach to the bottom of the bottle, 8 , if this is the case, we are better able to regulate the flow.

The Inhaler. -The pattern known as Schimmelbusch's is perhaps as suitable as any ; over it is placed a piece of stockinette bandage, which appears to answer more advantggeously than flannel, and may easily and instantaneously be changed; lastly, we require a strip of gauze rolled Into a ring, with a diameter sufficlently large to encircle the patient's nose and mouth; some use a piece of Gamgee tiasue, with a hole to admit the nose and mouth, which answers the purpose equally well.

The Method of Administration.-First place the Skinner's mask over the patient's face as in using it for chloroform; allow a few drops of ether to trickle on the mask, and when the patient has become used to the smell, put the ring pad of gauze round the nose and mouth, resting the Skinner's mask upon it, and increase the rate of flow of the ether by tilting the bottle; it is necessary to keep this flow constant, either at a diminished or increased rate, according to the requirements of the case.

In conclusion, I may say I have used this method in children and adults : with children, for example, in circumcision operations it appears to be universally satiefactory, and with adults it answers well in thin anaemic females or extremely exhausted subjects, but in the plethoric man or fat woman it requires much patience and much ether to produce an ansesthetic state.

There are one or two polnts which ought to be observed during administration; it is well to keep the patient's head Inclined, so that if mucus be secreted in excess it may not gravitate into the trachea and set up bronchial affections; should the inhaler inadvertently get too soaked, it also prevents any drops of ether getting into the farices, and so setting up violent coughing; these are untowards incidents which may happen during first efforts, and it is just as well to bear them in mind ; although $I$ trust eventualities, which may happen in any method of producing anaesthesia, will not prevent the adoption of this method should occasion arise.

IN a recent article on insurance companies, the Daily Telegraph says that of all those who work for these companies, few render such valuable service as do the medical examiners, but little is heard abjut them. The success of any company largely depends upon the skill with which the medical men connected with it do their work. There are some pitfalls in their path, but happily for insurance companies the medical profession as a whole possesses a very sensitive conscience, and the reports made are as accurate and as fair as possible. In everything to do with insurance work doctors as a whole have a very fine record. The tornado of scandal in connexion with insurance companies which ruined so many reputations in America not long ago, left those of medical men not only unsmirched but even unassailed.

\section{AN OPEN CONTINUOUS DROP METHOD OF} ADMINISTERING ETHER.

BY ALEXANDER BROWNLEE, F.R.C.S.E., HONORARY ANAESTHETIST, CARDIFF INHIRMARY.

With Remarks by

J. LynN THOMAs, C.B., F.R.O.S.

Ether, as 18 well known, bas been given in various open and semi-open methods for many years. For the past twelve months I have been giving ether by an open continuous drop method. Last January I read a short paper before the Cardiff Division of the British Medical Assoclation on the subject, and the present paper was in the courge of preparation when Dr. Gardner's article appeared, in the Journal of November 23rd. Mirs Alice Magaw, an American lady anaesthetist, records 14,000 cases of ether administered by the drop method "without a death directly due to the anaesthetic," and I am indebted to Mr. Lynn Thomas who saw ber practising it, for my Initial instruction in it.

The apparatus is simple and Inexpens ive. The mask is slightly larger than the ordinary Schimmelbusch's and fits the face more closely. It is covered with about 16 layers of sterilized gauze. The drop bottle is an ordinary $6 \mathrm{oz}$. bottle, with a plain cork in which two grooves are cut. One groove is larger than the other, and a strand of wool passes through it, the smaller groove allowing air to pass into the bottle and the ether coming out.by capillary action. By means of this slmple arrangement, a steady drop is obtained. Although I have trled many of the ordinary drop bottles, I have not been able to get the eame regular steady drop with one of them. I find it best to have $\mathbf{Z}$ drop bottles, the grooves in the corks being. cat so that a large drop is got from one and a smaller drop from the other. It is essential to bear in mind that ether should never be poured on the mask. If this be done, the result generally is that some ether gets into the patient's mouth, and there is an attack of coughing. In some of my early csses, in which I fell into this mistake, a rigid eondition of the abdominal wall was the result, and I had to dlspense with ether and "push" the administration of chloroform to overcome 1 .

The patient havlng been put on the table, the mask is placed on the face, and the administration commenced by slowly dropping ether on the mask until the patient becomes somewhat accustomed to the smell. The ether is then dropped more rapidly, and the mask surrounded, if necessary, by a towel until the patient's face is completely hidden. As the patient goes "under" the towel may be removed. The administration can then be continued with the smaller drop bottle. I am bound to say, however, that I find considerable difficulty in inducing anaesthesia in strong or alcohollc men by this means, and in the case of such subjects $I$ begin with a mixture of chloroform and ether (CHCl $_{3} 1$ part, ether 3 parts), get the patient fairly well under with this, and then continue with ether alone. Once ansesthesia is established there is no difficulty in maintaining it. In the cases of children, women, and in men in any way emaciated or weak, complete anaesthesia can be induced by this method with ether alone in from three to ten minutes.

Up to date I have conducted 257 administrations, and the results have been, I consider, highly satisfactory. The ages and conditions of the patients operated on have varled within wide limits. Thus my youngest patient was 2 years old; $m y$ eldest 73 . The cases have included all clases of patients-strong, healthy men, alcoholics, neurotic women, patients emaciated by malignant disease and other debilitating conditions, and serious accident cases. The shortest administration lasted seven minates, the longest three hours. In the great majority of the cases the condition of the patient was very satisfactory. There is not the anxiety assoclated with the administration of chloroform, while many of the objectlonable f atures of ether administration with the Clover or other closed apparatus are eliminated. There is less secretion of mucus than when the latter is employed, and the respiratory excnrsions of the abdominal wall are not 80 vigorous-a point not without importance to the surgeon in operations requiring fine manipulation. The breathing is invariably of a regular snoring type, the puplls 